\title{
Management of Investment and Innovation-Driven Development of Business Entities: Determinants of Workforce Activating
}

\author{
Irina R. Kirishchieva ${ }^{1,2}$ Mikhail M. Skorev ${ }^{1}$ Tatiana O. Grafova ${ }^{1,2, *}$ \\ Victoria I. Kirishchieva ${ }^{1}$
}

\author{
${ }^{1}$ Department of Economics, Accounting and Analysis, Rostov State Transport University, Rostov-on-Don 344038, Russia \\ ${ }^{2}$ Rostov Branch of Russian Customs Academy, Rostov-on-Don, 344002, Russia \\ *Corresponding author. Email: grafova_to@donrta.ru
}

\begin{abstract}
Investment and innovation-driven development of business entities represents one of the most important factors for improving the economic competitive ability. Managing this process assumes active involvement of a company's personnel. The present work proves the main role within the workforce activating in the investment and innovation-driven development of business entities to be assigned to the personnel management system. The factors contributing to the workforce activating in the investment and innovationdriven development should be as follows: the formation of an effective team at the enterprise, a working incentive system for the personnel, and the formation and maintenance of an appropriate internal culture. The determinants of workforce activating to involve them in the investment and innovation-driven development of a business entity are accompanied by a presentation of possible practices for each of the selected management activity types.
\end{abstract}

Keywords: business entity, management of investment and innovation-driven development, determinants of workforce activating, teamwork, incentive system, internal culture

\section{INTRODUCTION}

One of the important factors in increasing the competitiveness of the Russian economy is its innovative development [1], being primarily implemented at the business entity level. However, today the specified economy sector experiences a breaking crisis, primarily caused by the lack of innovation and investment model of the enterprises' marketing strategy in innovation management [2], which determines the instability of this process.

The success of investment and innovation activity is considerably shaped by a business entity workforce activating in this process. All of them participate in business and operations and directly or indirectly contribute to the development of the investment and innovation component of the enterprise.

This article is aimed at consolidation and systematization of information about the types and methods of management of investment and innovation-driven development of business entities by involving personnel in this process.

\section{MAIN FOCUS}

The main role within the workforce activating in the investment and innovation-driven development of business entities is assigned to the personnel management system, in which, from this perspective, special attention should be focused on the following:

- diagnosing recruitment needs, taking into account a business entity development strategy in the field of investment and innovative solutions;

- determination of the necessary number and qualifications of employees and staff composition;

- implementation of workforce policies aimed at improving the competencies and qualifications of personnel to provide their professional development;

- adaptation and involvement of employees in the system of investment and innovative development of the enterprise;

- formation of an incentive system providing the increase of the employees' interest in the results of a business entity's investment and innovation activity;

- coordination and regulation of interpersonal relations in such a way as to prevent the negative impact of this sphere's imbalance within the enterprise on the process of its investment and innovation activity management;

- formation of a business entity's effective internal culture to maintain the interest of employees in the investment and 
innovative development of the enterprise and its intellectual component.

\section{DETERMINANTS OF BUSINESS ENTITY WORKFORCE ACTIVATING}

\subsection{Teamwork}

One of the factors contributing to the workforce activating within the investment and innovation activity should include the formation of a successful team at the enterprise, since the performance of any organization depends not so much on the effort of individual employees as on the team's success [3]. This is based on the fact that collective intelligence is able to create a better innovative product than the one made by individual employees, even with the highest qualification level. Nevertheless, unfortunately, modern practice ignores the role of teamwork in managing the personnel of a business entity. At the same time, we assume that one can agree with such authors as T. D. Zinkevich-Evstigneeva, D. F. Frolov and T.M. Grabenko. In their work "Theory and practice of team building. Modern technology for creating of teams" [4], along with the production sphere, where teams are built, they gave prominence to intellectual area of activity, exposing the creative ability of personnel, associated with research, experiments, analysis and search for rational solutions. This undoubtedly accompanies the processes of investment and innovation-driven development of a business entity.

A team should be viewed as an independent organism, being able to adjust its activity [5, 6]. Synergistic cooperation of employees is essential within the teamwork; it must be competently built and based on effective interaction rules and procedures, providing constant information exchange. The team's employees should be selected in such a way that the developed solutions contribute to the improvement of business processes in the field of investment and innovation activity management within an economic entity. In these conditions, the team is not advised to have a consensus when solving the investment and innovation problems. In teamwork, it is necessary to unite employees expressing different points of view, applying non-traditional approaches to problem solving and having creative minds, which strengthens the whole team.

In the area of investment and innovation teamwork can provide the following advantages:

- achieving better possible results, dealing with issues collectively, rather than working with employees individually;

- stimulating a creative approach to investment and innovation problem solving;

- encouraging employees to express various original ideas and proposals;

- more in-depth analysis of issues;
- research of the problems solutions from various perspectives;

- getting new information from other employees, using different information resources;

- reducing risk in making ill-considered decisions in the investment and innovation activity workflow;

- improving the teamwork and mutual understanding among the employees dealing with the same problem;

- increasing level of employees' interest in the final results of work.

\subsection{Motivation and incentives}

An effective system of motivation and incentives for the employees should be considered to be one of the ways of workforce activating in the investment and innovationdriven development of business entities. It should be pointed out that motivation and incentive determinants, on the one hand, form the motivational basis of an individual worker, while, on the other hand, provide a motivational component for the entire personnel of a business entity, making the workforce activating in the investment and innovation-driven development of the enterprise possible. In this context, it is worthy of note that the personnel need may be fully or partially satisfied, along with possible lack of staff satisfaction, subsequently inducing the incentive elements implementation to be resumed.

One of the most effective modern business approaches to the process of employee engagement in investment and innovation activity of a business entity is represented by gamification, i.e. "using ideas from games, loyalty programs and behavioral economics to attract users" [7]. Gamification can be considered to be a tool for personnel involvement in the teamwork and interaction among them [8]. Gamification facilitates communication within the whole enterprise and among employees, and enables informal communication, which makes it easier to spread the ideas and get feedback on them.

According to Brian Burke, gamification should encourage people to do extraordinary things [9]. This approach should be simultaneously focused on achieving the goals by both employees and the business entity to implement gamification successfully. However, business performance benchmarks should encourage employees to achieve their own goals.

Motivated employees are interested in the work themselves, and therefore significantly reduce management expenses. Since they do not wait for the instructions, it is easier to control their performance, with them being concerned with the quality of work; the need for changes and innovations is more evident for such workers. The innovative capacity of the personnel is viewed as the main component in the search for innovative ways to implement the strategic aims and objectives of a business entity [10]. Motivated employees ensure the successful performance of a business entity and its development in the field of implementing the strategic 
objectives and its stable market position, which fully facilitates its activating in the investment and innovationdriven development of the organization. Motivated workers make the best use of the resources invested in business [11]. In this regard, constant employee engagement monitoring and diagnostics are necessary, and this should be considered the reason for increasing a company's financial results [12]. From our point of view, it is caused by the sufficient investment and innovation activity of a business entity.

Together with motivation, one more direction of workforce activating in the investment and innovation activity is worth mentioning, namely incentives for the employees, encouraging people to work effectively. Their expert knowledge in science and technology provides the innovative production within a business entity. Furthermore, the level of workforce activating in this field is proved by their innovative and investment proposals. This approach allows the investment and innovation activity management system to be associated with the activation of heuristic ideas of the personnel, contributing to the effective use of the intellectual assets.

Financial encouragement should become the main priority in the incentive system aimed at the workforce activating in this direction. Staff development and their skill level determine the innovation of their work and the ability to quickly adapt to changing market requirements.

Financial encouragement should be based on both fixed and variable parts of the incentives. In these circumstances, according to Amosova N. I., it is vital to [13]:

- define the goals and principles of a company's remuneration system;

- hold the information about the remuneration systems of other enterprises, in particular, the competitive ones;

- study the conditions for applying the relevant remuneration systems;

- analyze the effectiveness of the applied remuneration system by comparing the results obtained with the target. Incentive allowance is based on the results of the specific problem solution. Therefore, the variable part of the incentive must take into account both the employee's performance, and the one of his team, which stimulates the creative activity of the personnel and increases their motivation to develop unconventional solutions in the field of investment and innovation activity of the business entity. At the same time, it is possible to introduce individual bonus payments for special achievements in developing ideas concerning investment and innovations.

When forming a material incentive system, all the components of the personnel's performance should be considered, namely allowances for high-quality work, for overachievement of target, for initiative and creativity, that ensured positive effect in the field of investment and innovation activity.

It is important to bear in mind the need for transparency of the incentive system, making it possible for each employee to understand the exact reasons for receiving a reward. The effectiveness of the material incentive system depends on the fact that the extent of payment corresponds to the employee's performance and is entirely fair. The focus should be shifted from deciding on the amount of bonuses for the employees, performing similar activities, to the introduction of bonuses for the contribution made by each individual employee, depending on their overall performance.

It is important to note that moral encouragement can be expressed by the following means: the Recognition Board, representing not just good employees, but forwardthinking ones; possible career development; planning the rest leave and providing additional creative leave; expression of gratitude for high performance; publishing the results of the employee's work in the departmental edition; holiday gifts, etc. Moral encouragement is also possible to be implemented by staff training aimed at their creative potential development.

However, the situations, when the incentives do not work efficiently for the personnel, are worth mentioning. The reasons for it may be as follows:

- inconsistent incentive strategy, leading to misunderstanding of the grounds and dates of the payment; - lack of personnel motivation for investment and innovation activity;

- discrepancy between the employee's interests and the incentives proposed;

- getting used to the incentives, when an employee considers bonuses to be an indispensable element of their remuneration.

First of all, the investment and innovation activity of each individual employee, together with subsequent overall performance of a business entity, depends on the effectiveness of motivation and incentive system at the enterprise.

\subsection{Internal culture}

A certain role in workforce activating in the investment and innovation-driven development management of business entities should be assigned to the formation and maintenance of an appropriate internal culture, since it plays an important part in motivating individuals to a given type of activity. A well-built internal culture provides a comfortable atmosphere within the company and, as a result, creates conditions for positive business environment. And this is for a reason. According to B.V. Gabrielyan, one of the main internal culture priorities lies in "development of the system of internal motivational resource, taking into account the company's current tasks and modern technological trends" [14]. Internal culture is one of the effective means of attracting qualified employees to the enterprise. Such workers are able to effectively deal with investments and innovations, since the internal culture created at the enterprise largely determines the motivation and professional engagement. As noted by E. A. Ignatova and S. L. Feshchenko, the business entities with a clear-cut internal culture have the 
opportunity to make maximal use of human resources potential [15].

It should be taken into account that every business entity, regardless of its life-cycle stage, has a certain internal culture, which is expressed in the relations between the employees within the enterprise, their external communication, the attitude of the management to the personnel performance, including in the sphere of investment and innovation-driven development of the organization and activating of this work. Adaptation of the employee's corporate ideas and their compliance with the internal culture of the enterprise is an important factor of personnel involvement in the internal culture, focused on investment and innovation-driven development of the business entity. Only consistency and uniformity in the understanding of internal culture enables achieving the specified investment and innovation prospects of a business entity.

Based on the above stated, we can conclude that one of the tasks that can be solved at the business entity level, using an effective internal culture, is workforce activating in their investment and innovation-driven development, along with building an effective team that can raise the enterprise to the proper level of investment and innovation-driven development. Therefore, when selecting personnel capable of investment and innovation activity, it is necessary to take measures to retain such workers at the enterprise. Internal culture focused on promoting such employees certainly represents one of the possible ways to do this.

Such promotion should be provided to the employees capable of creative and critical thinking in the sphere of attracting investment and implementation of innovations at the enterprise, existing both inside and outside the entity; to those capable of competent substantiation of the possibility and practicability of their current use, to the workers with inventive thinking, interested in continuous self-improvement, training, education, skills enhancement in different fields, as the employee's outlook provides intersubject communications and allows to apply solutions from other areas to fulfill the tasks of investment and innovation-driven development of the business entity. In this respect, the internal culture should focus on the following areas:

- providing free creative communication among the employees of the business entity;

- building a communicative basis for personnel interaction on various issues, including investment and innovation activity;

- encouraging teamwork focused on investment and innovation-driven development of the business entity;

- hiring employees with progressive ideas concerning investment and innovation to the company;

- creating messaging related to investment and innovation both within the business entity and outside it;

- encouraging the company's personnel involvement along with investment and innovation activity;
- implementation of measures for creative development of personnel, providing them with scientific and practical knowledge;

- providing an opportunity to improve the skills and update the knowledge, skills and abilities of the company's personnel;

- enhancing the participation of employees in scientific conferences, forums and exhibitions in order to accumulate state-of-the-art knowledge related to the existing innovations in the areas of the company's concern; - including motivation and incentive tools into the internal culture to increase the investment and innovation workforce activity;

- development and maintainance of standards for personnel behavior to enhance their investment and innovation activity.

The implementation of the above mentioned measures makes the internal culture develop creative initiative in the business entity workforce and its involvement to the investment and innovation-driven development of the enterprise.

\section{CONCLUSION}

Thus, investment and innovation development management of a business entity by workforce activating in this process should be focused on building a personnel management system that determines this process, encouraging teamwork, cultivating a clear motivation and incentive system for this type of an enterprise activity with a detailed list of measures allowing implementation of each incentive factor, creating an effective internal culture aimed at the investment and innovation-driven development of the organization.

\section{REFERENCES}

[1] Kuznetsova O, N. Stimulation of Innovative Activities of Economic Actors // Bulletin of

The Financial University - 2017. - No. 1 (97). - P. 2834.

[2] Krempovaya N. L., Krempovaya M. K. Innovative Investment Strategies as the Main Way of Companies Development in Russia // Scientific Bulletin: Finance, banking, investment. - 2016. - No. 1. - P. 95-99.

[3] Solodova E. P., Kalmykova D. A., Polupan K. L. Team Building as a Modern Method for Human Resource Management // Vestnik of Samara University (Journal). Economics and Management. - 2018. volume 9. - No. 4. - P. 67-72.

[4] Zinkevich-Evstigneeva T. D., Frolov D. F., Grabenko T. M. Theory and Practice of Team Building. 
Modern Technology for Creating of Teams" / edited by T. D. Zinkevich-Evstigneeva. St. Petersburg: "Rech", 2004. 304 p.

[5] Charles J. Margerison. Team Leadership: A guide to Success with Team Management System. Thomson Learning (EMEA), 2002, 198 p.

[6] Robert Barner, Charlotte P. Barner. Building Better Teams: 70 Tools and Techniques for Strengthening Performance Within and Across Teams. John Wiley \& Sons Limited, 2012, 496 p.

[7] Zichermann, G. Gamification Revolution: How Leaders Leverage Game Mechanics To Crush the Competition / Gabe Zichermann, Joselin Linder ; translated by Ideliya Ayzatulova. - M. : Mann, Ivanov, and Ferber, 2014. — $272 \mathrm{p}$.

[8] Pershina E. G., Maslennikov P. V., Podzorova G. A. Use of Gamification in Personnel Management at the Enterprise // Management of Economic Systems: Scientific Electronic Journal. - 2017. - \% 2 (96). https://cyberleninka.ru/article/n/ispolzovaniegeymifikatsii-v-upravlenii-personalom-na-predpriyatii

[9] Brian Burke, Gamify: how gamification motivates people to do extraordinary things // Brookline (MA) : Bibliomotion, 2014. - 181 p.
[10] Kozina E. S. Integral Estimation and Development of the Innovative Potential of the Organization's Personnel // The Siberian Transport University Bulletin. - 2011. - No. 25. - P. 96-102.

[11] Kulagin V. P. Company's Investment Resources Management: Personnel Motivation Aspect // Russian Journal of Entrepreneurship. - 2018. - volume 19. No. 12. - P. 4159-4174

[12] Kachan P. A. Systematic Diagnostics of Motivation as Indices' Factor of Company's Activity // The Journal of Creative Economy. - 2010. - volume 4. - No. 9. - P. 85-88. - url:

https://creativeconomy.ru/lib/4310

[13] Amosova N. I. Motivation and Material Stimulation of Workers in Modern Conditions // Bulletin of the Kurgan State Agricultural Academy. 2015. - No. 2. - P. 48-51.

[14] Gabrielyan B. V. Internal Culture as a Basis for Employee Engagement // Current issues of economic sciences: LVI International Research and Training Conference materials. Under general editorship of S.S. Chernov. - Novosibirsk, 2017. - P. 38-46.

[15] Ignatova E. A., Feshchenko S. L. Corporate Culture as a Tool for Stimulation of Personnel // Territory of science. - 2018. - No. 5. - 79-83. 